\title{
Pore evolution in refractory gold ore formed by oxidation roasting and the effect on cyanide leaching process
}

Hui Li ${ }^{1}$, Zhihang Li ${ }^{2, *}$, Jianping Jin 1,*, Yuexin Han ${ }^{1,3,4}$, Yanjun Li ${ }^{1,3}$

${ }^{1}$ School of Resources and Civil Engineering, Northeastern University, Shenyang 110004, China;

${ }^{2}$ School of Earth Science and Resources, Chang'an University, Xi'an 710054, China;

${ }^{3}$ National-local Joint Engineering Research Center of High-efficient Exploitation Technology for Refractory Iron Ore Resources, Shenyang 110004, China

${ }^{4}$ State Key Laboratory of Rolling and Automation, Northeastern University, Shenyang 110004, China

Supporting Information: The XRD result shows that the main mineral phases in the carbonaceous gold ore are quartz, dolomite, graphite, calcite, and pyrite. The carbonaceous matters lead to the preg-robbing effect.

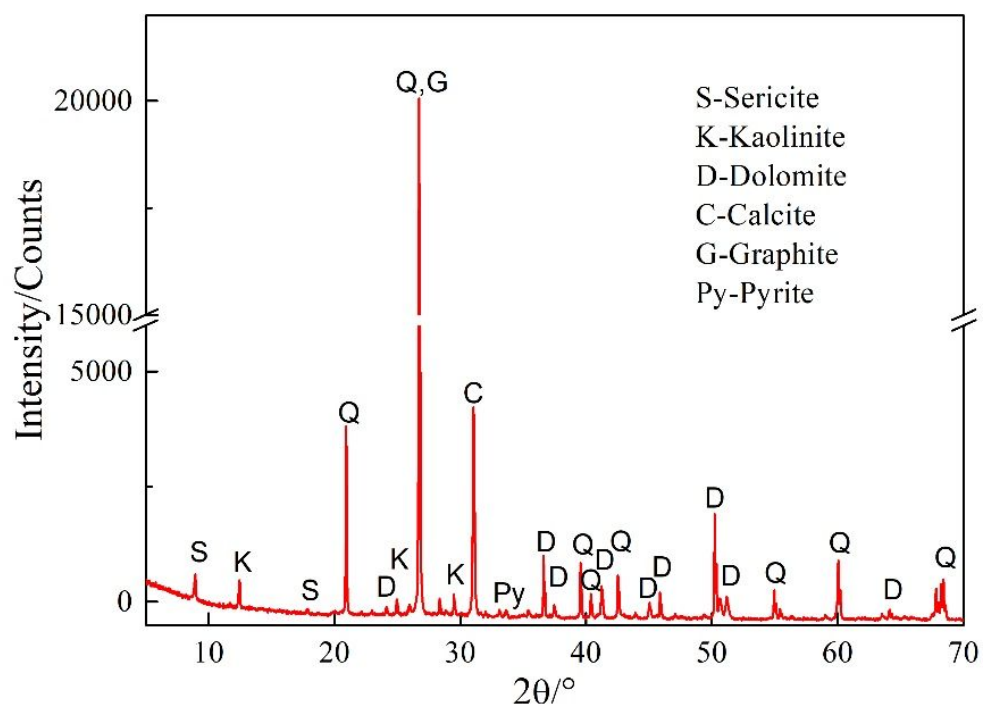

Figure S1. XRD spectrum of raw ore

Supporting Information: The result of chemical phase analysis of carbon indicates that the total carbon content is $6.39 \%$, including $1.33 \%$ organic carbon and $1.50 \%$ graphitic carbon. The remaining $3.56 \%$ of carbon comes from carbonate minerals. 
Table S1. Chemical phase analysis of carbon in the raw ore $/ \%$

\begin{tabular}{ccccc}
\hline Component & Inorganic & Organic & Graphitic & Total \\
\hline Content & 3.56 & 1.33 & 1.50 & 6.39 \\
\hline
\end{tabular}

